\title{
Core-shell poly(lactide-co-\&-caprolactone)-gelatin fiber scaffolds as pH-sensitive drug delivery systems
}

\author{
Qingqing Sang ${ }^{1}$, Heyu Li ${ }^{1}$, Gareth R. Williams ${ }^{2, *}$, Huanling Wu ${ }^{1}$, Li-Min Zhu ${ }^{1,3, *}$ \\ ${ }^{1}$ College of Chemistry, Chemical Engineering and Biotechnology, Donghua University, Shanghai \\ 201620, China \\ ${ }^{2}$ UCL School of Pharmacy, University College London, 29-39 Brunswick Square, London, WC1N 1AX, \\ $U K$ \\ ${ }^{3}$ Key Laboratory of Science \& Technology of Eco-Textiles, Ministry of Education, Donghua University, \\ Shanghai 201620, China
}

* Corresponding authors:

Prof. L.M. Zhu

Tel: +8621 62372655,

E-mail:1zhu@dhu.edu.cn

Dr. G.R. Williams

Tel: +44 (0) 2077535868 ,

E-mail:g.williams@ucl.ac.uk 


\section{Abstract}

Dual-drug-loaded pH-responsive fiber scaffolds were successfully prepared by coaxial electrospinning. These were designed with the aim of being sutured into the resection site after tumor removal, to aid recovery and prevent cancer recurrence. The shell was made up of a mixture of gelatin and sodium bicarbonate ( $\mathrm{SB}$, added to provide $\mathrm{pH}$-sensitivity), and was loaded with the anti-inflammatory drug ciprofloxacin; the core comprised poly(lactide-co-e-caprolactone) with the chemotherapeutic doxorubicin hydrochloride (DOX). Scanning electron microscopy revealed most fibers were smooth and homogeneous, with average diameters of 750-850 $\mathrm{nm}$. Transmission electron microscopy demonstrated the presence of a clear core/shell structure in all the materials. The fiber scaffolds were further characterized using infrared spectroscopy and X-ray diffraction, which proved that both drugs had been successfully loaded into the fibers in the amorphous form. The gelatin shells were cross-linked with glutaraldehyde to enhance their stability, and water contact angle measurements used to confirm they remained hydrophilic after this process, with angles between 10 and $35^{\circ}$. This is important for onward applications, since a hydrophilic surface is known to encourage cell proliferation. During in vitro drug release studies, a rapid and acid-responsive release of ciprofloxacin was seen, accompanied by sustained and long-term DOX release. Both the release profiles and the mechanical strength of the fibers can effectively be tuned through the SB content of the fibers: for instance, the break stress varies from 2.00 $\mathrm{MPa}$ to $2.57 \mathrm{MPa}$ with an increase in SB content. The $\mathrm{pH}$ values of aqueous media exposed to the scaffolds decrease only slightly, by less than $0.5 \mathrm{pH}$ units, over the two-month timescale, suggesting that only minimal fiber degradation occurs during this time ( $\mathrm{HCl}$ from the DOX salt and the degradation products of gelatin and PLCL are all acidic materials, and will cause a reduction in $\mathrm{pH}$ of the immersion medium if freed into solution). The fiber scaffolds also have good biocompatibility, as revealed by in vitro cytotoxicity experiments. Overall, our results demonstrate that the novel scaffolds reported here are promising $\mathrm{pH}$-sensitive drug delivery systems, and may be candidates for use after tumor resection surgery.

Keywords: Anti-cancer; Coaxial electrospinning; pH-responsive; Dual-drug-loaded; Polymer Fiber 


\section{Introduction}

In this work, we sought to develop pH-responsive dual-drug loaded systems to be applied to tumor resection sites with the aim of preventing both infection and the recurrence of cancer. To do this, we employed the electrospinning technology, a simple route to prepare nanoscale fibers that has been widely explored in the context of biomaterials ${ }^{1}$. The simplest experiment, single-fluid spinning, applies electrical energy to a polymer solution containing a functional component (e.g. a drug), to yield monolithic fibers. A more sophisticated variant is coaxial electrospinning, where two different solutions are flowed through two concentrically arranged needles to produce core/shell architectures. Electrospinning's simplicity, low cost, and the fact that a wide variety of materials can be processed, have led to many reports of electrospun fibers ${ }^{2,3}$.

Coaxial fibers have several benefits over the monolithic fibers from single fluid spinning, as a result of their more complex architectures allowing greater control over functional performance. For instance, a core/shell structure can extend the period over which drug contained in the core is released if the shell comprises a blank polymer layer. In one such study, Yu et al. ${ }^{4}$ used poly( $\varepsilon$-caprolactone) (PCL) as the shell polymer and a mixture of a protein and polyethylene glycol as the core, and explored the relationship between drug release rate and shell thickness. It was found that a thicker shell layer slows down the rate of release. Drexler and co-workers ${ }^{5}$ prepared fibers with a PCL shell and gelatin core, and determined that the two polymers together led to materials with high biocompatibility (as a result of gelatin) and good mechanical properties (from PCL). In other work, Duan et al. selected PCL as the core polymer and collagen as the shell, producing fibers which possess both good mechanical strength and high biocompatibility, and which they proposed might be used in vascular tissue engineering 6 .

The tumor microenvironment is rather more acidic than the physiological $\mathrm{pH}$, and higher temperature $^{7,8}$, which offer the opportunity to target therapies. A number of $\mathrm{pH}$-sensitive drug delivery systems have been reported. For example, Ulbrich et al. ${ }^{9}$ synthesised hydrolyzed poly(maleic anhydride) and $\mathrm{N}$-(2-hydroxypropyl) conjugates of acrylamide, and linked doxorubicin (DOX) to the polymer backbone. These conjugates were found to be stable at $\mathrm{pH}$ 
7.4 but released their drug cargo at pH 5. Further, Chiang and co-workers ${ }^{10}$ prepared a dual $\mathrm{pH}$ - and temperature-sensitive DOX-loaded nanogel based on pol(N-isopropylacrylamide); they were able to use temperature changes to regulate the loading of DOX, and control its release by changing the $\mathrm{pH}$.

A number of electrospun systems with $\mathrm{pH}$ sensitivity have been reported. These typically used a pH-sensitive polymer (such as a Eudragit) as the basis for the fibers. Another route to achieve this is to use sodium bicarbonate (SB). For instance, Zhao et al. ${ }^{11}$ fabricated acid-responsive electrospun fibers using an emulsion method (loading SB and ketoprofen into PLLA fibers), and in a previous study we found that preparing gelatin fibers loaded with SB can lead to the $\mathrm{pH}$-responsive release of ciprofloxacin ${ }^{12}$. In other work, Ke and co-workers ${ }^{13}$ prepared a drug delivery system based on microspheres of poly(lactic-co-glycolic) acid containing DOX and SB, which exhibited the ability to target intracellular compartments with $\mathrm{pHs}$ lower than the general physiological $\mathrm{pH}$. The incorporation of SB leads to acid sensitivity because it reacts with protons at low $\mathrm{pH}$, generating $\mathrm{CO}_{2}$ gas. This produces pores or ruptures in the drug-carrying vehicles, rapidly releasing the incorporated active ingredient. Thus, SB has been demonstrated in these pioneering studies to offer a simple and low-cost route to acid sensitivity. However, all these studies only looked at a single active ingredient.

The development of new cancer medicines is of great importance: data from the World Health Organization show that by 2020 the global incidence of cancer will increase by $50 \%$ over 2003 levels, which equates to an additional 15 million cancer patients per year ${ }^{14}$. The main treatments for cancer have comprised surgery, radiotherapy, and chemotherapy. In general, surgical resection is the most effective treatment where tumors are accessible ${ }^{15}$. However, this can induce an infection, and inflammation associated with tumor-infiltrating inflammatory cells can affect the efficacy of adjuvant chemotherapies used alongside surgery. Chemotherapy also generally uses high doses of the relevant active ingredients, which leads ot numerous toxic side effects on the body. Regardless of the treatment used, recurrence of cancer is very common: relapse is seen in one of every five cancer cases ${ }^{16}$.

One area of drug delivery in which electrospun fibers have attracted particular attention is that of anti-cancer medicines. In one example, Sedghi and co-workers ${ }^{17}$ recently developed a curcumin-loaded monolithic system based on poly(vinyl alcohol) and chitosan, which they 
proposed have to applications in post-operative chemotherapy. In another, doxorubicin (DOX)-loaded mesoporous silica nanoparticles were incorporated into poly(L-lactic acid) (PLLA) fibers via electrospinning, giving systems from which DOX was released in a sustained manner ${ }^{18}$.

In this paper, we sought to build on the literature reports to make multi-functional materials with both anti-inflammatory and anti-cancer properties. To do this, we fabricated acid-responsive fiber scaffolds carrying ciprofloxacin and DOX. The intention is that the fiber scaffolds can be sutured into the resection site after tumor removal. They were thus designed to provide an initial short-term release of ciprofloxacin, to inhibit any infection and post-operative inflammation, followed by long-term DOX release to destroy any residual cancerous tissue and avoid recurrence. The experimental rationale is illustrated in Figure 1. A series of systems with different SB contents were prepared in the hope of tuning the drug release and mechanical properties. For the latter, we envisage that the scaffolds would be sutured into the resection site post-surgery to secure them in place ${ }^{19-21}$. This requires them to have a break stress in the range of 2 to $5 \mathrm{MPa}^{22,23}$.

Ciprofloxacin is a quinolone drug which offers broad-spectrum antimicrobial activity with no serious side effects ${ }^{24}$. It was selected for inclusion in the fiber shell, with the goal of preventing post-operative infections. Doxorubicin hydrochloride, included in the core, is an anti-tumor drug which inhibits the synthesis of nucleic acids and has broad anti-tumor activity. The core polymer is poly(lactide-co- $\varepsilon$-caprolactone) (PLCL), which can be fully hydrolyzed in vivo. The final degradation products of PLCL are water and carbon dioxide, and the intermediate products (lactic acids) are harmless to the human body in small quantities ${ }^{25}$. PLCL thus has good biocompatibility and does not lead to any toxic side effects in vivo. It has been widely used in tissue engineering of cartilage, bone, blood vessels, the liver, and the heart, inter alia ${ }^{26,27}$. The presence of PLCL in the fibers made in this work can impart the fiber scaffolds with suitable mechanical properties to act as a tissue engineering scaffold in the later stages of post-operative recovery, and since it hydrolyzes slowly ${ }^{28,29}$ should give sustained release of the embedded DOX to prevent recurrence. The shell polymer, gelatin, is a naturally occurring material with good biocompatibility and biodegradability, as well as a 
high degree of hydrophilicity ${ }^{30}$. It will thus ensure the fiber scaffolds produced have a hygroscopic exterior, which is expected to enhance biocompatibility.

\section{Experimental section}

\section{Materials}

Gelatin (powder, purity > 99.5\%) and glacial acetic acid were obtained from the Sinopharm Chemical Reagent Co., Ltd. Doxorubicin hydrochloride (DOX, purity > 99\%) was procured from J\&K Scientific Co. Ltd, while dimethyl sulfoxide (DMSO), and poly(lactide-co- $\varepsilon$-caprolactone) (PLCL) (PCL:PLLA=1:1, $\left.\mathrm{Mw}=34.5 \times 10^{4} \mathrm{~g} \quad \mathrm{~mol}^{-1}\right)$ were purchased from Jinan Daigang Biomaterials Co., Ltd. RPMI 1640, DMEM and fetal bovine serum (FBS) were sourced from Jinuo Biological Medicine Technology Ltd. 1,1,1,3,3,3-Hexafluoroisopropanol (HFIP, purity > 95.5\%), ciprofloxacin (purity>98\%), phosphate-buffered saline ( $\mathrm{PBS}, \mathrm{pH}=7.4)$, sodium bicarbonate $(\mathrm{SB})$, penicillin/streptomycin, and Thiazolyl Blue Tetrazolium Bromide (MTT) were purchased from Sigma-Aldrich Ltd. An acetate buffer (AA, pH=5.0) was prepared in-house. SMMC-7721 and L929 cells were provided by the Institute of Biochemistry and Cell Biology (Chinese Academy of Sciences).

\section{Electrospinning}

A stainless steel co-axial spinneret (Changsha Nayi) was used for electrospinning. The spinneret dimensions were as follows: core needle inner diameter (ID) $0.346 \mathrm{~mm}$ and outer diameter (OD) $0.607 \mathrm{~mm}$; shell needle ID $1.138 \mathrm{~mm}$ and OD $1.476 \mathrm{~mm}$. A simple flat-tipped needle with an internal diameter of $0.5 \mathrm{~mm}$ was also employed to prepare monolithic control fibers. The core and shell solutions were prepared in HFIP, as detailed in Table 1 ("G" denotes gelatin, "P" PLCL, and "S" sodium bicarbonate; “+” indicates systems with a drug loading, and "-" those without drug). All solutions were stirred for 24 hours on a magnetic stirrer to ensure complete dissolution.

For electrospinning, the appropriate solutions were loaded into $5 \mathrm{~mL}$ plastic syringes, and expelled through the co-axial spinneret with shell and core flow rates of $0.7 \mathrm{~mL} \mathrm{~h}^{-1}$ and $0.3 \mathrm{~mL} \mathrm{~h}^{-1}$ respectively. A high voltage power supply (ZGF-2000, Shanghai Sute Electrical 
Co. Ltd.) was used to apply a voltage of $17 \mathrm{kV}$ between the spinneret and an aluminium collector plate $(10 \times 10 \mathrm{~cm})$. Two syringe pumps (KDS100, Cole-Parmer) were used to drive the working fluids. The distance between the spinneret and collector plate was $23 \mathrm{~cm}$. Control monolithic gelatin and PLCL fibers were similarly prepared, using a single needle and a flow rate of $0.5 \mathrm{~mL} \mathrm{~h}^{-1}$.

All experiments were performed at $25^{\circ} \mathrm{C}$ and 33-45\% relative humidity. After about 7 hours of electrospinning, the resultant fiber mats were dried in a vacuum chamber (DZF-6050, Shanghai Laboratory Instrument Work Co. Ltd.) for 48 hours at $25^{\circ} \mathrm{C}$. The gelatin shells were then crosslinked. To do this, an aqueous solution of glutaraldehyde $(25.0-28.0 \%(\mathrm{v} / \mathrm{v}) ; 10 \mathrm{~mL})$ was placed in a Petri dish at the bottom of a brown translucent desiccator, with the fibers above them. Crosslinking was allowed to proceed in the glutaraldehyde vapor for $9 \mathrm{~h}$. All of the polymer solutions and fiber scaffolds containing DOX were stored away from light in order to prevent any degradation.

\section{Fiber morphology}

Fiber samples $(1 \times 1 \mathrm{~cm})$ were mounted on metal stubs using conductive double-sided tape, and then sputter coated with platinum under argon for about $40 \mathrm{~s}$. A scanning electron microscope (SEM; JSM-5600 instrument, JEOL) was employed to investigate the morphological characteristics of the fibers. The ImageJ software (National Institutes of Health) was used to analyze the average diameter of each fiber sample. Around 50 fibers in the SEM images were randomly selected for this purpose.

Transmission electron microscopy (TEM; H-800 instrument, Hitachi) was additionally used to confirm the core/shell structure of the fibers. Samples for TEM were prepared by spinning directly onto copper TEM grids for a few seconds.

\section{Fiber characterization}

The water contact angles of the fiber surfaces were determined using a $322 \mathrm{~W}$ instrument (Thermo Cahn). A water droplet (ca. $1 \mu \mathrm{L})$ was placed onto the surface of the fibers for this, with at least 10 measurements made (at $25^{\circ} \mathrm{C}$ ) per fiber sample. Fourier-transform infrared spectroscopy (FTIR) was performed on a Nicolet-Nexus 670 FTIR spectrometer (Nicolet 
Instrument Corporation), over the scanning range $600-4500 \mathrm{~cm}^{-1}$ and with a resolution of 2 $\mathrm{cm}^{-1}$. X-ray diffraction (XRD) patterns were collected over the $2 \theta$ range $6-70^{\circ}$ on a D/Max-BR diffractometer (Rigaku) supplied with $\mathrm{Cu} \mathrm{K \alpha}$ radiation $(40 \mathrm{kV} / 30 \mathrm{~mA}, \lambda=1.5418$ $\AA$ ). The mechanical properties of the cross-linked fibers were quantified on a HY-9940FS tensile testing machine (Shanghai Heng Yuyi Co., Ltd). Measurements were performed at 25 ${ }^{\circ} \mathrm{C}$ and a relative humidity of $70 \%$; samples of the fiber scaffolds of $1 \times 5 \mathrm{~cm}$ (thickness 0.1 $0.2 \mathrm{~cm}$ ) were cut for these experiments. Five measurements were made for each fiber sample, and the results are reported as mean \pm S.D.

\section{In vitro ciprofloxacin and $\mathrm{DOX}$ release}

The cross-linked drug-loaded fibers $(100 \mathrm{mg})$ were immersed in centrifuge tubes containing $20 \mathrm{~mL}$ of PBS $(\mathrm{pH}=7.4)$ or acetate buffer $(\mathrm{pH}=5.0)$. The samples were incubated in a constant temperature incubator shaker at $37^{\circ} \mathrm{C}$ for three weeks, with mild shaking (100 $\mathrm{rpm})$. At predetermined time points, $1 \mathrm{~mL}$ of the test medium was withdrawn and an equal amount of fresh preheated PBS or AA buffer solution was added. The amount of drug released was quantified using a UV spectrophotometer (UV-1800, SHJH Company) at 277 $\mathrm{nm}$ (ciprofloxacin) or $480 \mathrm{~nm}$ (DOX), following construction of a calibration curve. Dilution was corrected for in the release calculations, and the cumulative release is expressed as a percentage of the theoretical drug loading in the fibers. Three measurements were made for each fiber sample, and the results are reported as mean \pm S.D.

\section{Antibacterial activity}

The antibacterial activity of the fibers was measured using the zone of inhibition test method in Luria-Bertani medium. E. coli (ATCC 29522) and S. aureus (ATCC 6538) were used as model gram-negative and gram-positive bacteria. The crosslinked fiber scaffolds were cut into circular discs (diameter ca. $14 \mathrm{~mm}$ ), then disinfected with three $2 \mathrm{~h}$ cycles of exposure to UV radiation prior to use. Bacteria were cultivated in the liquid medium for $12 \mathrm{~h}$ at $37^{\circ} \mathrm{C}$ in a rotary shaker. The $\mathrm{pH}$ of the medium was then adjusted to 6.8 , and $100 \mu \mathrm{L}\left(10^{5}\right.$ colony forming units) of the bacteria loaded into a petri dish by the plate coating method. Next, the fiber samples were placed onto the plates. All the dishes were cultured at $37^{\circ} \mathrm{C}$ for 
$12 \mathrm{~h}$, before zones of inhibition were measured. Five measurements were made for each fiber sample, and the results given as mean \pm S.D.

\section{In vitro cytotoxicity experiments}

SMMC-7721 (a human liver cancer cell line) was employed to study the efficacy of the fibers in inducing the death of cancer cells, and L929 (mouse fibroblast) cells as a model non-cancerous cell line to explore the cytotoxicity of the scaffolds to normal cells. These cells were cultured in RPMI 1640 and DMEM medium, respectively. Before use, both RPMI 1640 and DMEM medium were supplemented with $1 \%(\mathrm{v} / \mathrm{v})$ of a pre-made penicillin (100 units

$\left.\mathrm{mL}^{-1}\right)$ and streptomycin $\left(100\right.$ units $\left.\mathrm{mL}^{-1}\right)$ solution, and 10\% (v/v) fetal bovine serum. Cells were cultured in an incubator at $37^{\circ} \mathrm{C}$ and $5 \% \mathrm{CO}_{2}$. Prior to experiments, trypsinization was used to separate the cells from the culture flask, after which they were recovered by centrifugation and diluted to a density of $2.0 \times 10^{4}$ cells $\mathrm{mL}^{-1}$. Fiber samples for in vitro studies were directly electrospun onto $14 \mathrm{~mm}$ cover slips, with 20 cover slips placed on the collector and electrospinning conducted for $7 \mathrm{~h}$. The fibers were cross-linked with glutaraldehyde, and any residual glutaradehyde vapour allowed to evaporate before cell culture experiments were performed.

The fiber-coated cover slips were placed in the wells of 24-well plates, with fiber-free slips as a negative control. The 24-well plates were sterilized under alcohol steam for $48 \mathrm{~h}$ and then washed twice with PBS to remove any residual ethanol. Next, $400 \mu \mathrm{L}$ of RPMI 1640 (for SMMC-7721 cells) or DMEM (for L929 cells) was added to each well and the plate incubated for $0.5 \mathrm{~h}$ before $200 \mu \mathrm{L}$ of dissociated SMMC-7721 or L929 cells at a density of 2.0 $\times 10^{4}$ cells $\mathrm{mL}^{-1}$ were seeded directly into each well. After 1,3 , or 5 days, the medium in each well was replaced by $40 \mu \mathrm{L}$ of MTT solution $(0.5 \% \mathrm{w} / \mathrm{v})$ and $360 \mu \mathrm{L}$ of fresh RPMI or DMEM. After incubation for $5 \mathrm{~h}, 400 \mu \mathrm{L}$ DMSO was added to each well, and the plate placed on a shaker for $30 \mathrm{~min}$ at room temperature. Cell viability was then quantified in terms of absorption at $570 \mathrm{~nm}$ with the aid of a microplate reader (Multiskan, Thermo-Fisher). Each experiment contained triplicate conditions, with three independent experiments performed.

\section{Degradation studies}


Approximately $0.1 \mathrm{~g}$ of each fiber sample was soaked in $20 \mathrm{~mL}$ of PBS or AA buffer solution in a $37^{\circ} \mathrm{C}$ incubator. After either 3 days or 2 months of incubation, the fiber samples were recovered, and surface water removed. $1 \times 1 \mathrm{~cm}$ samples were cut from the mats and analysed using SEM. The $\mathrm{pH}$ of the immersion medium was also quantified using a $\mathrm{pH}$ meter (PHS-3C, Inesa Instrument Co. Ltd). Five measurements were made for each fiber sample.

\section{Statistical analysis}

The experimental data are presented as mean \pm SD. Statistical analysis was undertaken using one-way ANOVA. The threshold significance level was set at 0.05. Thus, p (probability) values lower than 0.05 were considered statistically significant.

\section{Results and discussion}

\section{Fiber morphology}

Figure 2(a)-(d) depict SEM images of $\mathrm{G}^{+} / \mathrm{P}^{+}, \mathrm{GS}_{1}{ }^{+} / \mathrm{P}^{+}, \mathrm{GS}_{2}{ }^{+} / \mathrm{P}^{+}$, and $\mathrm{GS}_{3}{ }^{+} / \mathrm{P}^{+}$, and reveal that the fiber scaffolds are largely smooth and homogeneous. The SEM images for $\mathrm{GS}_{1}^{-} / \mathrm{P}^{-}, \mathrm{GS}_{1}^{-} / \mathrm{P}^{-}, \mathrm{GS}_{2}^{-} / \mathrm{P}^{-}$, and $\mathrm{GS}_{3}^{-} / \mathrm{P}^{-}$can be found in the Supplementary Information, Figure S1. Clearly, most of the fiber diameters are homogeneous, but some very fine fibers can also be observed. The diameter of the fibers increase with drug loading, which is presumably a result of the greater amount of solute per unit volume dispensed. The addition of SB causes the fiber diameters to become slightly larger (compare for instance Figure 2(a) and (b)), but the amount of SB added has little effect on diameter. The diameters of monolithic drug-loaded gelatin and PLCL fibers have previously been reported to be smaller than these coaxial materials, at $603 \pm 126 \mathrm{~nm}$ and $732 \pm 130 \mathrm{~nm}$ respectively ${ }^{12}$.

Figure 2(e)-(h) show the drug-loaded fibers after cross-linking. The morphology has barely changed, but the fibers have become larger. There is also a decrease in the void volume of the fiber scaffolds after crosslinking, and they become slightly yellow in colour. Crosslinking with glutaraldehyde involves the reaction of free amino groups on the gelatin polypeptide chains with the aldehyde groups of glutaraldehyde (forming aldimine $[\mathrm{CH}=\mathrm{N}]$ linkages) ${ }^{31}$. In the first step, the nucleophilic addition of $\varepsilon-\mathrm{NH}_{2}$ groups to carbonyl groups of the aldehyde results in the formation of carbinolamine, which is unstable. In the second step, 
protonation of the -OH group followed by loss of an $\mathrm{H}_{2} \mathrm{O}$ molecule leads to conjugated Schiff bases being generated. Therefore, new covalent bonds are formed between gelatin molecules both intramolecularly and intermolecularly. These result in the fiber scaffolds' mechanical strength and water resistance improving significantly, with an increased tensile strength having been reported after crosslinking ${ }^{32}$. The SB content (or lack thereof) has no effect on the post-cross-linking diameters.

TEM images (Figure 3 and S1) show the drug-loaded fibers to have a clear core/shell structure. As the SB concentration increases, some solid particles (assumed to be SB) can be seen in the shell. This is expected to be because the concentration was above its saturation solubility, and thus the shell working fluid comprised a suspension at higher concentrations. Nevertheless, at an SB concentration of $5 \%$ w/v clear compartmentalized fibers can still be seen. However, when the SB content reaches 7\%, a phase separation phenomenon arises. The $\mathrm{GS}_{4}{ }^{+} / \mathrm{P}^{+}$system shows a large number of solid particles on the surface of fibers by SEM, and no clear coaxial structure in TEM (see Figure S2). This formulation was thus excluded from further analysis.

\section{Further characterization}

FTIR spectra can be found in Figure 4. Gelatin has peaks at $3296 \mathrm{~cm}^{-1}$ attributed to $-\mathrm{OH}$ or -NH stretching, and two broad peaks at about $1659 \mathrm{~cm}^{-1}$ and $1539 \mathrm{~cm}^{-1}$, which correspond to the stretching of the $\mathrm{C}=\mathrm{O}$ group (amide I), and the combined bending of $\mathrm{N}-\mathrm{H}$ and stretching of C-N in the amide II band ${ }^{33,34}$. The characteristic band of PLCL at $1758 \mathrm{~cm}^{-1}$ arises from ester bonds $(-\mathrm{C}(=\mathrm{O}) \mathrm{O}-)$, while that at $2943 \mathrm{~cm}^{-1}$ corresponds to methylene $\left(-\mathrm{CH}_{2}\right)$ groups. Ciprofloxacin has peaks at $3050 \mathrm{~cm}^{-1}$ (attributable to O-H stretching), $1620 \mathrm{~cm}^{-1}$ ( $\mathrm{C}=\mathrm{O}$ stretching), $1600 \mathrm{~cm}^{-1}$ and $1500 \mathrm{~cm}^{-1}$ (benzene ring stretching vibrations). Absorbance bands are observed for DOX at around at $3310 \mathrm{~cm}^{-1}$ and $2933 \mathrm{~cm}^{-1}$ as a result of $-\mathrm{NH}_{2}$ and -CH stretching, while those at $1350 \mathrm{~cm}^{-1}$ and $1070 \mathrm{~cm}^{-1}$ arise from $\mathrm{C}-\mathrm{H}$ stretching and the asymmetric stretching vibration of the ether linkage (C-O-C).

The drug-loaded fibers contain characteristic bands at $2943 \mathrm{~cm}^{-1}, 1659 \mathrm{~cm}^{-1}$ and 3296 $\mathrm{cm}^{-1}$ which are correlated with the presence of both PLCL and gelatin. The presence of the drugs is less clear, because their distinctive vibrations (e.g. that of DOX at $3050 \mathrm{~cm}^{-1}$ ) overlap 
with those of gelatin and PLCL. This can most likely be ascribed to the low drug loading and these peaks being masked by gelatin.

X-ray diffraction patterns of the fibers (Figure S3) show only broad haloes, demonstrating a lack of long-range order. The fibers hence comprise amorphous systems, with the drugs distributed in them at the molecular level ${ }^{35}$.

\section{Contact-angle data and mechanical properties}

Contact-angle data were collected to assess the wettability and hydrophilicity of the fiber membrane surfaces. This is important because it impacts the biocompatibility of the scaffolds, and the ability of cells to adhere to and proliferate on them. The results for all the samples are summarized in Table 2. As expected, the fibers with gelatin shells all have hydrophilic surfaces, with contact angles below $35^{\circ}$. PLCL is hydrophobic, and accordingly PLCL fibers have a high contact angle of $>120^{\circ}$. The contact angle of the fibers decreases with an increase in the $\mathrm{SB}$ content in the shell, but only for $\mathrm{SB}$ concentrations up to $3 \% \mathrm{w} / \mathrm{v}\left(\mathrm{GS}_{2}{ }^{+} / \mathrm{P}^{+}\right)$: a further increase in the concentration to $5 \% \mathrm{w} / \mathrm{v}$ in $\mathrm{GS}_{3}{ }^{+} / \mathrm{P}^{+}$makes little difference. Generally speaking therefore, increasing the concentration of SB appears to increase the hydrophilicity of the fibers. Comparing the drug-free and drug-loaded fibers, it can be seen that the addition of ciprofloxacin and DOX reduces the contact angle slightly, owing to their hydrophilic nature.

Appropriate mechanical properties are necessary for scaffold materials. To probe the mechanical properties of the electrospun scaffolds, their tensile strength was measured for the monolithic gelatin and PLCL fibers, and the coaxial fiber scaffolds. Representative results are shown in Figure 5.

All the fibers display similar behavior, as can be seen from the full data set in Table 3 . The two components of the fiber act synergistically to optimize the mechanical properties: PLCL has high strength, and as a result the coaxial fibers show higher tensile strength values then gelatin alone. Conversely, gelatin has higher elongation at break, which is also imparted on the coaxial fibers such that they stretch more than pure PLCL before breaking. The addition of gelatin in the core/shell fibers reduces this dramatically, to $<0.1 \mathrm{MPa}$, very close to the value for pure gelatin fibers. The results obtained are in line with those found in the 
literature. For instance Jaiswal et al. ${ }^{36}$, prepared two types of polycaprolactone-gelatin-hydroxyapatite scaffolds. One scaffold was prepared by depositing hydroxyapatite on electrospun polycaprolactone-gelatin fibers, and the second by blend electrospinning. The break stress of the scaffolds was found to be $c a .3 \mathrm{MPa}$ and $c a .1 \mathrm{MPa}$ respectively. The agglomeration of hydroxyapatite particles reduced the mechanical properties of the blend electrospun scaffold. In another study by Yaszemski ${ }^{37}$, a synthetic material to replace trabecular bone was developed and found to have a break stress of $c a .5$ MPa. Zhou ${ }^{38}$ prepared a regenerated silk fibroin tubular scaffold using electrospinning, and found it to have a tensile strength of $3.57 \mathrm{MPa}$, suitable for use in small-diameter vascular grafts. Our fiber scaffolds are found to have break stresses within the range 2-2.6 MPa and elongation at break of $>20 \%$. This suggests that they match the requirements for being sutured (a break stress of $2-5 \mathrm{MPa}^{23}$ ), and thus are suitable for use as implants in resection sites.

\section{Drug release}

Figure 6 presents ciprofloxacin release profiles from the fiber scaffolds (prepared as in Table 1) in PBS $(\mathrm{pH}=7.4)$ or AA $(\mathrm{pH}=5.0)$. While the sodium bicarbonate (SB)-free systems behave very similarly in both PBS and AA, acidic conditions are found to promote ciprofloxacin release in the SB-containing fibers. The latter bodes well for their use in treating infection, given that inflammation is known to lower the local $\mathrm{pH}^{39}$. The $\mathrm{pH}$-sensitivity arises because at low $\mathrm{pH} \mathrm{CO}_{2}$ gas is generated as $\mathrm{SB}$ reacts with protons ${ }^{40}$, creating channels and forming a porous structure through which the drug molecules can diffuse into the release medium (see Figure 1). Typically, infections arise in the first few days after surgery ${ }^{41,42}$, and thus the release rates observed from the fiber scaffolds match well with the clinical requirement.

DOX release data can be found in Figure 7. Release from a uniaxial PLCL fiber scaffold (Figure 7(a)) shows rapid release over $c a .20$ hours in PBS (pH=7.4). In contrast, DOX release from the coaxial fibers in either PBS or AA buffer is much extended (Figure 7(b)) as a result of the core/shell structure ${ }^{43}$. As with ciprofloxacin, $\mathrm{pH}$-sensitivity is observed for the SB-containing fibers, with more rapid release in AA. This is promising for the treatment of 
cancer, given the lower $\mathrm{pH}$ of the tumor microenvironment than general physiological conditions. Cancer can reoccur at a range of times after resection, from the first week to the second year ${ }^{44-46}$. The DOX release profiles are thus very promising to prevent recurrence in the early weeks after surgery.

The drug release rates are governed by the degradation and porosity of the fibers. After the scaffolds are immersed in a buffer solution, their void volume is reduced due to the swelling of the cross-linked gelatin (which can absorb water to form a hydrogel) ${ }^{47}$, which contributes to sustained release profiles for drug loaded fiber scaffolds. Over longer periods of time, the fibers will begin to degrade through hydrolysis, losing their mechanical and structural integrity and further promoting drug release. Clearly, the total amount of drug released is higher from the SB-containing fibers, as is the rate of release (Table 4). As discussed above, the SB can react in acidic media to form channels through which the drug can diffuse into the release medium. The greater the content of SB, the more channels which can form, and thus the faster the drugs are freed from the fibers and the greater the eventual cumulative percentage release obtained. SB on the scaffold surface can also enhance wettability ${ }^{48}$, which further promotes DOX and ciprofloxacin release. It is important to note that the results in Table 4 are fully consistent with clinical needs: the scaffolds given a rapid initial, $\mathrm{pH}$-sensitive, release of ciprofloxacin to inhibit inflammation and infection, and long-term DOX release for the treatment of cancer.

In previous work ${ }^{12}$ we have explored ciprofloxacin release from monolithic PLCL/SB/drug and gelatin/SB/drug fibers. We found that the former had no $\mathrm{pH}$-sensitivity, regardless of the SB loading, while the latter show $\mathrm{pH}$-responsive release over around $24 \mathrm{~h}$. By combining both PLCL and SB we are able to obtain systems that are both $\mathrm{pH}$ sensitive and able to provide long-term sustained release.

\section{Antibacterial activity}

Figure 8 illustrates the antibacterial effects of the fiber scaffolds in terms of their inhibition zones. All the fibers have similar behavior, as can be seen from the full data set in Table 5. The samples loaded with ciprofloxacin kill all the bacteria around them, resulting in 
a clear inhibition zone of $30-40 \mathrm{~mm}$. Generally speaking, the inhibition zones against $S$. aureus are slightly greater than in the case of E. coli. This is consistent with the literature ${ }^{49}$. The addition of SB is found to have a small influence on the antibacterial properties of the fibers: the higher the SB content, the greater the inhibitory zone. This is consistent with the more rapid and greater extents of ciprofloxacin release observed with elevated SB concentrations.

\section{Biocompatibility}

To evaluate the fibers' biocompatibility, cells were seeded onto the different scaffolds and their growth monitored over 5 days. The results of MTT cell viability measurements obtained with non-cancerous L929 cells are given for the drug-loaded fibers in Figure 9(a) and for the drug free analogues in Figure S4(a). As expected, the number of cells present increases from day 1 to day 5 in all cases. Compared with the negative control (blank coverslips), there is a noticeable increase in the number of cells on all the fiber scaffolds, regardless of if they were drug-loaded or drug-free. Furthermore, an increase in the SB content (for instance from $\mathrm{G}^{+} / \mathrm{P}^{+}$to $\mathrm{GS}_{3}{ }^{+} / \mathrm{P}^{+}$) led to an increase in cell growth due to the increase in surface wettability of the scaffolds ${ }^{50}$. Overall, the data demonstrate that the fibers are not toxic to non-cancerous cells, regardless of whether they have a drug loading or not.

The analogous data obtained with SMMC-7721 cells are presented in Figure 9(b) and Figure S4(b). A rapid increase in the number of SMMC-7721 cells on the drug-free scaffolds $\mathrm{G}^{-} / \mathrm{P}^{-}, \mathrm{GS}_{1}^{-} / \mathrm{P}^{-}, \mathrm{GS}_{2}^{-} / \mathrm{P}^{-}$and $\mathrm{GS}_{3}^{-} / \mathrm{P}^{-}$is seen in Figure $\mathrm{S} 4(\mathrm{~b})$, analogous to the findings with the non-cancerous L929 cells. In the case of the drug-loaded scaffolds, at all time points studied there are fewer cells present than with the negative control. The drug-loaded scaffolds thus have the ability to inhibit the growth of cancer cells over the 5-day time period. These data are promising for the intended application of the fibers, although it is not possible to draw any conclusions from them regarding the longer-term performance of the fibers. However, given that DOX release continues over 26 - 30 days, it is thought that the fibers would continue to have efficacy over this period.

\section{Scaffold degradation}


SEM images of the fiber scaffolds after immersion in PBS or AA are presented in Figure 10. The fibers have merged after immersion, and their diameters become thicker compared with the initial fibers. An increase in the amount of SB in the materials leads to the generation of solid particles on the surface of the fibers (see Figure 10(d), 10(h)). This is thought to be because $\mathrm{CO}_{2}$ generated from the SB created channels in the fibers, permitting the migration of drug and SB to the fiber surface. These trends are apparent to a certain extent after three days, but are much clearer after two months' immersion. The reduction in void volume in the fibers is likely to explain the fact that drug release does not reach $100 \%$ : some of the drug is trapped deep inside the fibers, and as they swell and merge it becomes increasingly difficult for these molecules to escape into the release milieu.

The $\mathrm{pH}$ values of the immersion buffers were also explored at the end of the experiment (Figure 11). In both buffers, there is a small $(<0.5 \mathrm{pH}$ units) decline in $\mathrm{pH}$ after two months. This is likely to be in part a result of $\mathrm{HCl}$ in the DOX salt being freed from the fibers ${ }^{51}$. The degradation products of gelatin and PLCL are also acidic materials, and these too will contribute to the lowering of the $\mathrm{pH}$.

Overall, it is clear that partial degradation occurs over the two month timescale. This compares favorably with the literature and clinical requirements. In a study by Cao et al. ${ }^{52}$, porous scaffolds of polyglycolic acid and beta-tricalcium phosphate showed partial degradation 90 days after surgery. Wiltfang and co-worders 53 explored tricalcium phosphate implants into minipig tibial bone defects, and found 60\% degradation after 16 weeks and $80 \%$ at 28 weeks. Hence, the fibers have suitable biodegradability to act as scaffolds after the resection of tumors.

\section{Conclusions}

Novel $\mathrm{pH}$-sensitive coaxial fibers carrying ciprofloxacin and DOX were prepared in this work, with the aim of making scaffolds which could be implanted following tumor resection surgery. These were designed to provide an initial short-term release of ciprofloxacin, to inhibit any infection and post-operative inflammation, followed by long-term DOX release to destroy any residual cancerous tissue and avoid recurrence. The fibers comprised a 
biocompatible gelatin shell loaded with ciprofloxacin, and a poly(lactide-co- $\varepsilon$-caprolactone) core containing doxorubicin (DOX). SB was included in the shell to provide $\mathrm{pH}$-sensitivity. The fibers were generally smooth and cylindrical in shape, with clear core/shell compartments. They have hydrophilic surfaces, as shown by contact angle measurements. In drug release experiments, the shell rapidly released ciprofloxacin over a few days to quickly eliminate any post-surgery infection or inflammation, while the core gave long-term release of DOX to kill any residual cancer cells and prevent recurrence. The results of cytotoxicity tests demonstrated that the drug-loaded fiber scaffolds stimulated the growth of non-cancerous cells owing to their hydrophilic surfaces, but were able to inhibit the proliferation of cancerous cells. The electrospun materials display appropriate mechanical properties for scaffold materials, and suitable biodegradability to act as bioresorbable systems. Overall, the materials prepared in this work have great potential to be used as implantable scaffolds in order to prevent the recurrence of tumor after resection surgery.

\section{Acknowledgements}

This investigation was supported by grant 16410723700 from the Science and Technology Commission of Shanghai Municipality, the Biomedical Textile Materials "111 Project" of the Ministry of Education of China (No. B07024), and the UK-China Joint Laboratory for Therapeutic Textiles (based at Donghua University).

\section{References}

1. Gualandi C, Celli A, Zucchelli A, et al. Nanohybrid Materials by Electrospinning. Springer International Publishing, 2014, p.87-142.

2. Llorens E, Ibañez H, Del Valle LJ, et al. Biocompatibility and drug release behavior of scaffolds prepared by coaxial electrospinning of poly(butylene succinate) and polyethylene glycol. Materials Science \& Engineering C 2015; 49: 472-484.

3. Weili S, Jianxin H, Feng S, et al. Coaxial electrospun aligned tussah silk fibroin nanostructured fiber scaffolds embedded with hydroxyapatite-tussah silk fibroin nanoparticles for bone tissue engineering. Materials Science \& Engineering C Materials for Biological Applications 2016; 58: 342-351.

4. Yu H, Jia Y, Yao C, et al. PCL/PEG core/sheath fibers with controlled drug release rate fabricated on the basis of a novel combined technique. International Journal of Pharmaceutics 2014; 469: 17-22. 
5. Drexler JW and Powell HM. Regulation of electrospun scaffold stiffness via coaxial core diameter. Acta Biomaterialia 2011; 7: 1133-1139.

6. Duan N, Geng X, Ye L, et al. A vascular tissue engineering scaffold with core-shell structured nano-fibers formed by coaxial electrospinning and its biocompatibility evaluation. Biomedical Materials 2016; 11: 035007.

7. Yu X, Yang X, Horte S, et al. A pH and thermosensitive choline phosphate-based delivery platform targeted to the acidic tumor microenvironment. Biomaterials 2014; 35: 278-286.

8. Tannock IF and Rotin D. Acid pH in tumors and its potential for therapeutic exploitation. Cancer Research 1989; 49: 4373-4384.

9. Ulbrich K, Etrych T, Chytil P, et al. Antibody-targeted polymer-doxorubicin conjugates with pH-controlled activation. Journal of Drug Targeting 2004; 12: 477-489.

10. Chiang WH, Huang WC, Chang YJ, et al. Doxorubicin- Loaded Nanogel Assemblies with pH/Thermo- triggered Payload Release for Intracellular Drug Delivery. Macromolecular Chemistry \& Physics 2014; 215: 1332-1341.

11. Jingwen Z, Shen L, Bin L, et al. Stable acid-responsive electrospun biodegradable fibers as drug carriers and cell scaffolds. Macromolecular Bioscience 2013; 13: 885-892.

12. Sang Q, Williams GR, Wu $\mathrm{H}$, et al. Electrospun gelatin/sodium bicarbonate and poly(lactide-co-e-caprolactone)/sodium bicarbonate nanofibers as drug delivery systems. Materials Science \& Engineering C Materials for Biological Applications 2017; 81: 359-365.

13. Ke CJ, Su TY, Chen HL, et al. Smart Multifunctional Hollow Microspheres for the Quick Release of Drugs in Intracellular Lysosomal Compartments †. Angewandte Chemie 2011; 50: 8086-8089.

14. Rassool GH. Global cancer rates could increase by $50 \%$ to 15 million by 2020 . Ons News $2003 ; 44: 7-8$.

15. Coffey JC, Wang JH, Smith MJ, et al. Excisional surgery for cancer cure: therapy at a cost. Lancet Oncology 2003; 4: 760-768.

16. Grivennikov SI, Greten FR and Karin M. Immunity, inflammation, and cancer. Cell 2010; 140: 883-899.

17. Sedghi R, Shaabani A, Mohammadi Z, et al. Biocompatible electrospinning chitosan nanofibers: A novel delivery system with superior local cancer therapy. Carbohydrate Polymers 2017; 159: 1-10.

18. Qiu K, He C, Feng W, et al. Doxorubicin-loaded electrospun poly(L-lactic acid)/mesoporous silica nanoparticles composite nanofibers for potential postsurgical cancer treatment. Journal of Materials Chemistry B 2013; 1: 4601-4611. 
19. Moseley J. Alexis Carrel, the man unknown. Journey of an idea. Jama the Journal of the American Medical Association 1980; 244: 1119-1121.

20. Lusis AJ. Atherosclerosis. Nature 2000; 407: 233.

21. Chaparro FJ, Matusicky ME, Allen MJ, et al. Biomimetic microstructural reorganization during suture retention strength evaluation of electrospun vascular scaffolds. Journal of Biomedical Materials Research Part B Applied Biomaterials 2015; 104: 1525-1534.

22. Ino JM, Sju E, Ollivier V, et al. Evaluation of hemocompatibility and endothelialization of hybrid poly(vinyl alcohol) (PVA)/gelatin polymer films. Journal of Biomedical Materials Research Part B Applied Biomaterials 2013; 101: 1549-1559.

23. Stasiak J, Nair S and Moggridge GD. Mechanical strength of sutured block copolymers films for load bearing medical applications. Bio-medical materials and engineering 2014; 24: 563-569.

24. Ciprofloxacin: a quinoline antibacterial with minimal side effects. Inpharma 1985; 500: 6-7.

25. Wang JL and Dong CM. Synthesis, Sequential Crystallization and Morphological Evolution of Well- Defined Star- Shaped Poly( $\varepsilon$ - caprolactone)- b- poly(L- lactide) Block Copolymer. Macromolecular Chemistry \& Physics 2006; 207: 554-562.

26. Kim SH, Jung Y and Kim SH. A biocompatible tissue scaffold produced by supercritical fluid processing for cartilage tissue engineering. Tissue Engineering Part C Methods 2013; 19: 181-188.

27. Sartoneva R, Haaparanta A, LahdesVasama T, et al. Characterizing and optimizing poly-l-lactide-co- $\varepsilon$-caprolactone membranes for urothelial tissue engineering. Journal of the Royal Society Interface 2012; 9: 3444-3454.

28. Fernández J, Etxeberria A and Sarasua J-R. Synthesis, structure and properties of poly(L-lactide-co- $\varepsilon \varepsilon$ mathContainer Loading Mathjax -caprolactone) statistical copolymers. Journal of the Mechanical Behavior of Biomedical Materials 2012; 9: 100-112.

29. J F, A E and JR S. Synthesis, structure and properties of poly(L-lactide-co-e-caprolactone) statistical copolymers. Journal of the Mechanical Behavior of Biomedical Materials 2012; 9: 100-112.

30. Kim YH, Furuya H and Tabata Y. Enhancement of bone regeneration by dual release of a macrophage recruitment agent and platelet-rich plasma from gelatin hydrogels. Biomaterials 2014; 35: 214-224.

31. Farris S, Song $\mathbf{J}$ and Huang Q. Alternative reaction mechanism for the cross-linking of gelatin with glutaraldehyde. Journal of Agricultural \& Food Chemistry 2010; 58: 998-1003. 
32. Chioua BS, Bechtel PJ, Jafri H, et al. Cold water fish gelatin films: Effects of cross-linking on thermal, mechanical, barrier, and biodegradation properties. European Polymer Journal 2008; 44: 3748-3753.

33. Kuila $\mathrm{T}$, Bose $\mathrm{S}$, Khanra $\mathrm{P}$, et al. Characterization and properties of in situ emulsion polymerized poly(methyl methacrylate)/graphene nanocomposites. Composites Part A 2011; 42: 1856-1861.

34. Hashim DM, Man Y, Norakasha R, et al. Potential use of Fourier transform infrared spectroscopy for differentiation of bovine and porcine gelatins. Food Chemistry 2010; 118: 856-860.

35. Mafra L, Santos SM, Siegel R, et al. Packing interactions in hydrated and anhydrous forms of the antibiotic Ciprofloxacin: a solid-state NMR, X-ray diffraction, and computer simulation study. Journal of the American Chemical Society 2012; 134: 71-74.

36. Jaiswal AK, Chhabra H, Soni VP, et al. Enhanced mechanical strength and biocompatibility of electrospun polycaprolactone-gelatin scaffold with surface deposited nano-hydroxyapatite. Materials Science \& Engineering C Materials for Biological Applications 2013; 33: 2376-2385.

37. Yaszemski MJ, Payne RG, Hayes WC, et al. The ingrowth of new bone tissue and initial mechanical properties of a degrading polymeric composite scaffold. Tissue Engineering 1995; 1: 41-52.

38. Zhou J, Cao C and Ma X. A novel three-dimensional tubular scaffold prepared from silk fibroin by electrospinning. International Journal of Biological Macromolecules 2009; 45: 504-510.

39. Edlow DW and Sheldon WH. The $\mathrm{pH}$ of inflammatory exudates. Proceedings of the Society for Experimental Biology \& Medicine Society for Experimental Biology \& Medicine 1971; 137: 1328-1332.

40. Yuan Z, Zhao J, Zhu W, et al. Ibuprofen-loaded electrospun fibrous scaffold doped with sodium bicarbonate for responsively inhibiting inflammation and promoting muscle wound healing in vivo. Biomaterials Science 2013; 2: 502-511.

41. Maitland AI. Postoperative infection. Radiologic Clinics of North America 2006; 44: 439-450.

42. Lee JH, Lee JH, Kim JB, et al. Normal Range of the Inflammation Related Laboratory Findings and Predictors of the Postoperative Infection in Spinal Posterior Fusion Surgery. Clinics in Orthopedic Surgery 2012; 4: 269-277.

43. Zhang YZ, Wang X, Feng Y, et al. Coaxial electrospinning of (fluorescein isothiocyanate-conjugated bovine serum albumin)-encapsulated poly(epsilon-caprolactone) nanofibers for sustained release. Biomacromolecules 2006; 7: 1049-1057. 
44. Colleoni M, O'Neill A, Goldhirsch A, et al. Identifying breast cancer patients at high risk for bone metastases. Journal of Clinical Oncology Official Journal of the American Society of Clinical Oncology 2000; 18: 3925-3935.

45. Kim JK, Ha HK, Han DJ, et al. CT analysis of postoperative tumor recurrence patterns in periampullary cancer. Abdominal Imaging 2003; 28: 0384-0391.

46. Ghodratollah R, Anoshirvan K and Sanambar S. Determination of affected risk factors on time to recurrence and death in patients with postoperative gastric cancer using copula function. Journal of Research in Health Sciences 2014; 14: 52-56.

47. Munj HR, Lannutti JJ and Tomasko DL. Understanding drug release from PCL/gelatin electrospun blends. Journal of Biomaterials Applications 2016; 6: 933-949

48. Cui $\mathrm{W}, \mathrm{Li} \mathrm{X}, \mathrm{Zhu} \mathrm{X}$, et al. Investigation of drug release and matrix degradation of electrospun poly(DL-lactide) fibers with paracetanol inoculation. Biomacromolecules 2006; 7: 1623-1629.

49. Chin NX and Neu HC. Post-antibiotic suppressive effect of ciprofloxacin against gram-positive and gram-negative bacteria. American Journal of Medicine 1987; 82: 58-62.

50. Fadeeva E, Schlie S, Koch J, et al. Femtosecond Laser-Induced Surface Structures on Platinum and Their Effects on Surface Wettability and Fibroblast Cell Proliferation. Brill, 2009, p.163-172.

51. Tian Y, Bromberg L, Lin S, et al. Complexation and release of doxorubicin from its complexes with pluronic P85-b-poly (acrylic acid) block copolymers. Journal of Controlled Release 2007; 121: 137-145.

52. Cao H and Kuboyama N. A biodegradable porous composite scaffold of PGA/beta-TCP for bone tissue engineering. Bone 2010; 46: 386-399.

53. Wiltfang J, Merten HA, Schlegel KA, et al. Degradation characteristics of alpha and beta tri-calcium-phosphate (TCP) in minipigs. Journal of Biomedical Materials Research 2002; 63: 115-121. 


\section{Figures}

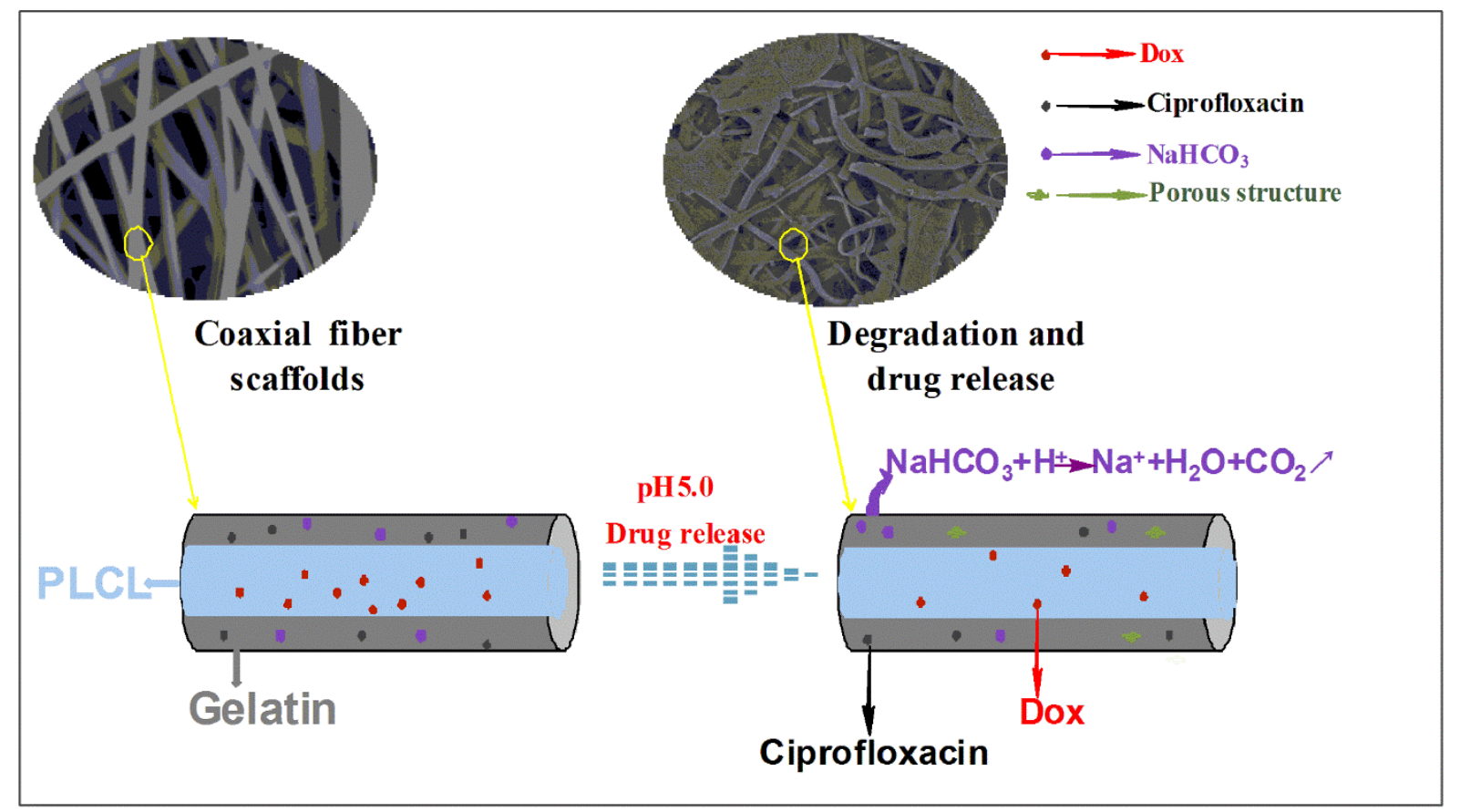

Figure 1. A schematic illustration of the experimental strategy used in this work. 

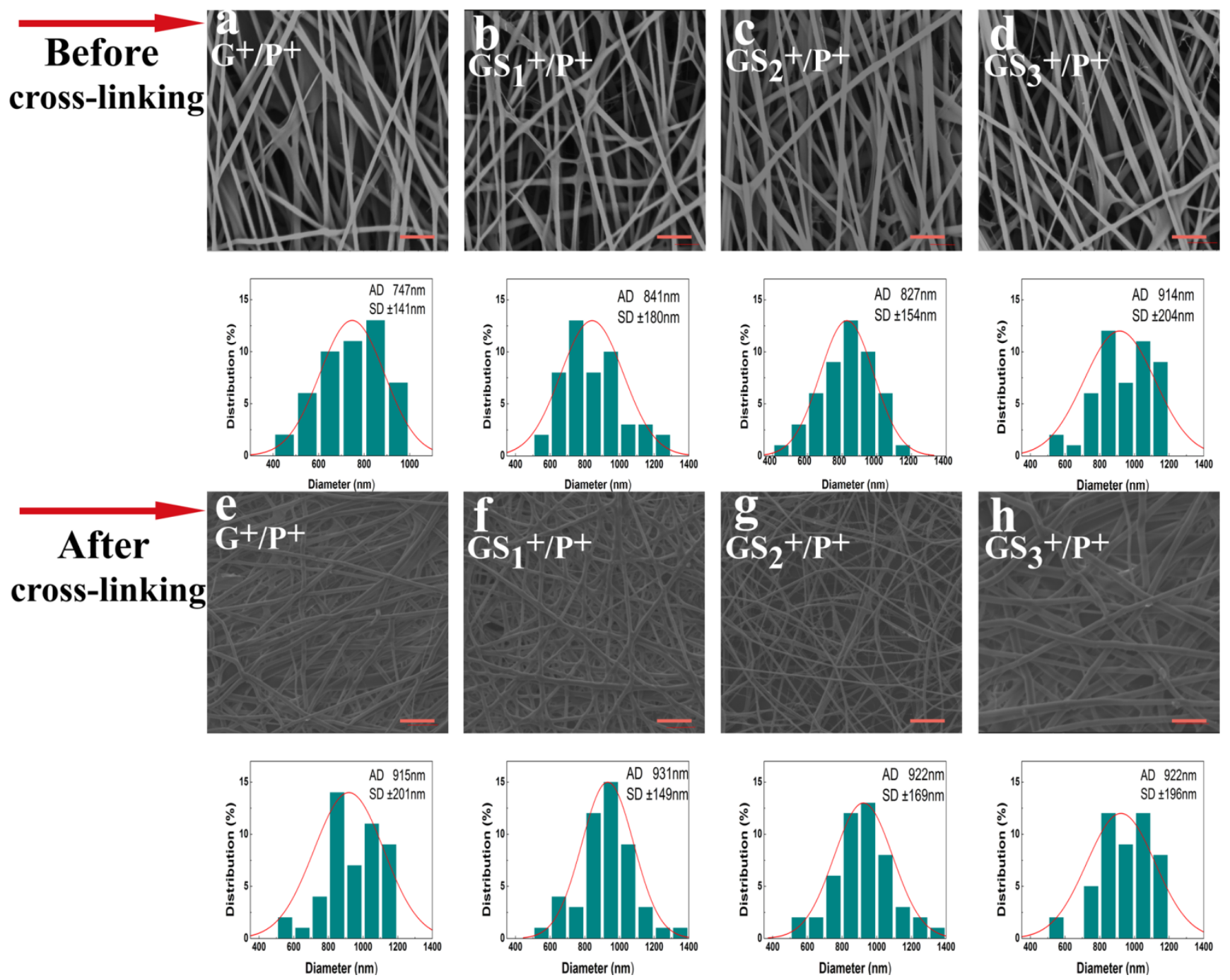

Figure 2. SEM images of the fibers generated: (a) $\mathrm{G}^{+} / \mathrm{P}^{+}$; (b) $\mathrm{GS}_{1}{ }^{+} / \mathrm{P}^{+}$; (c) $\mathrm{GS}_{2}{ }^{+} / \mathrm{P}^{+}$; (d) $\mathrm{GS}_{3}{ }^{+} / \mathrm{P}^{+}$; and (e-h) the same fibers after cross-linking. The diameter distributions are shown below the images (AD: mean diameter; SD: standard deviation). $\mathrm{G}^{+} / \mathrm{P}^{+}, \mathrm{GS}_{1}{ }^{+} / \mathrm{P}^{+}, \mathrm{S}_{2}{ }^{+} / \mathrm{P}^{+}, \mathrm{S}_{3}{ }^{+} / \mathrm{P}^{+}$are drug-loaded coaxial fiber scaffolds with $0 \%$, $1 \%, 3 \%$, and $5 \% \mathrm{w} / \mathrm{v}$ SB in the shell solution respectively. Scale bar: $5 \mu \mathrm{m}$. 

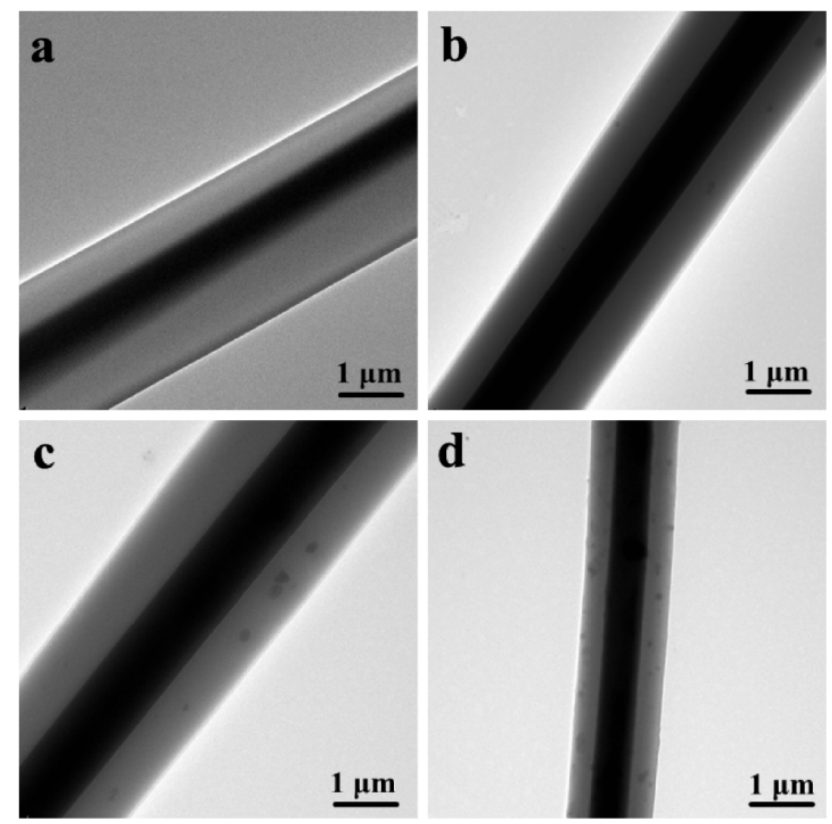

d

$\underline{1 \mu \mathrm{m}}$

Figure 3. TEM images of the coaxial fibers: (a) $\mathrm{G}^{+} / \mathrm{P}^{+}$; (b) $\mathrm{GS}_{1}+/ \mathrm{P}^{+}$; (c) $\mathrm{GS}_{2}{ }^{+} / \mathrm{P}^{+}$; and (d) $\mathrm{GS}_{3}{ }^{+} / \mathrm{P}^{+}$.

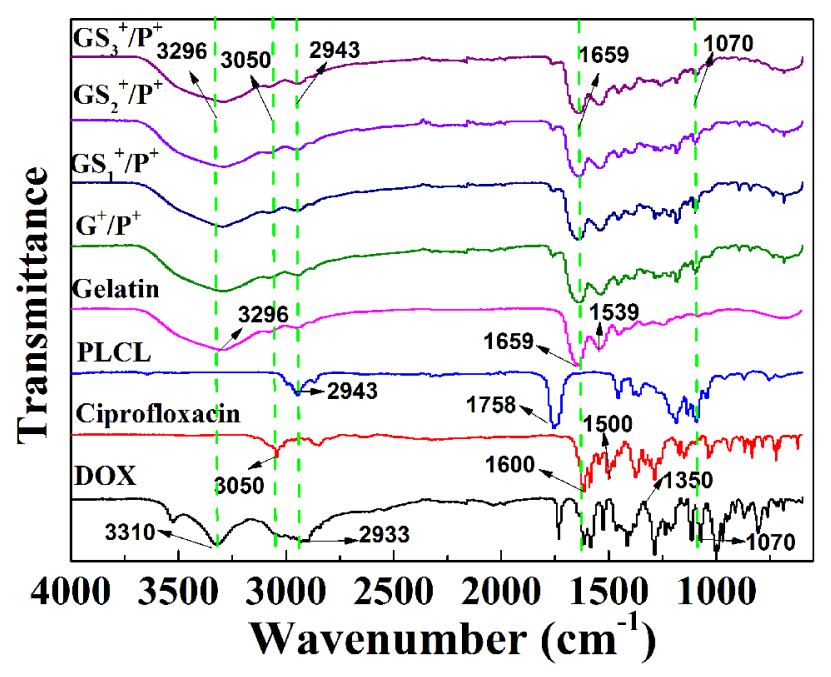

Figure 4. FTIR spectra of ciprofloxacin, DOX, monolithic gelatin and PLCL fibers, and the different coaxial fibers. 


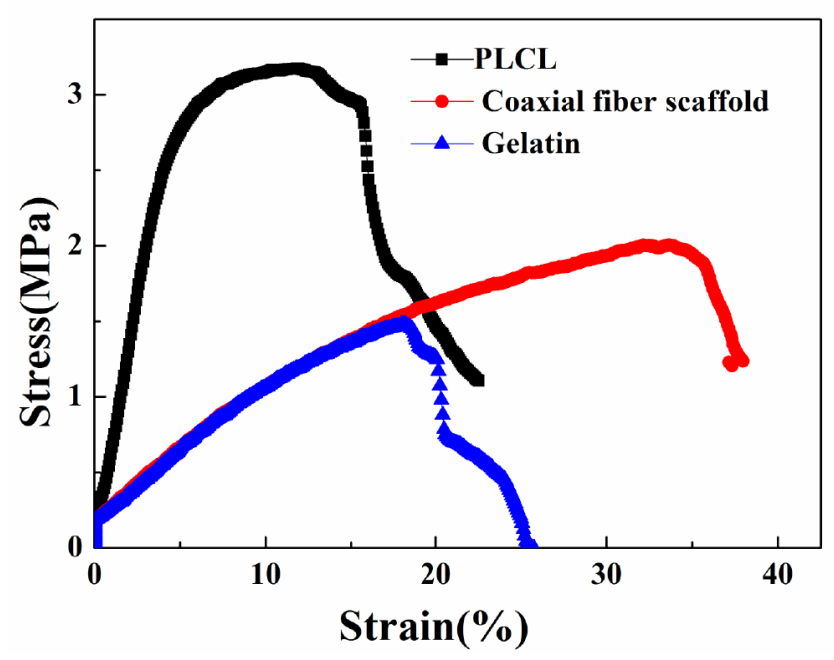

Figure 5. Stress/strain curves of monolithic gelatin and PLCL fibers, and the coaxial $\mathrm{GS}_{3}{ }^{+} / \mathrm{P}^{+}$material.

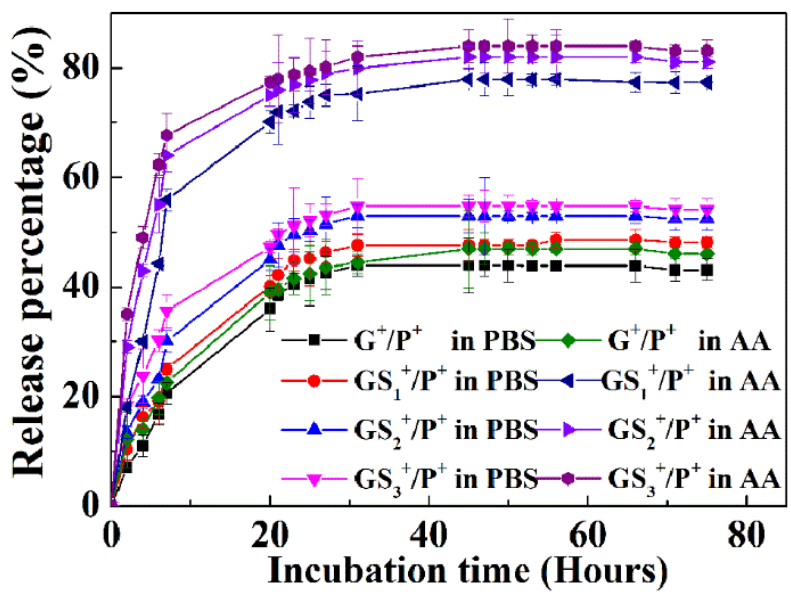

Figure 6. Ciprofloxacin release from the coaxial fibers in PBS $(\mathrm{pH}=7.4)$ or $\mathrm{AA}(\mathrm{pH}=5.0)$. 

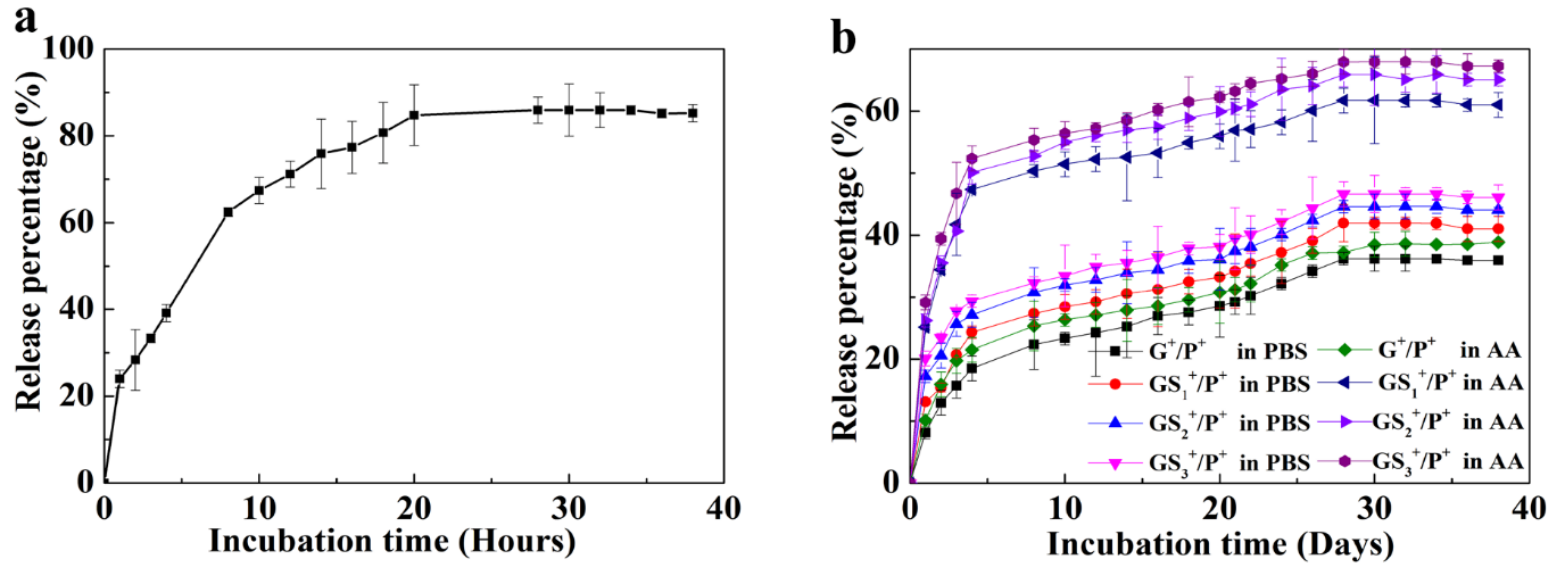

Figure 7. DOX release from (a) monolithic PLCL fibers in PBS $(\mathrm{pH}=7.4)$ and (b) the coaxial fibers in PBS $(\mathrm{pH}=7.4)$ or $\mathrm{AA}(\mathrm{pH}=5.0)$.
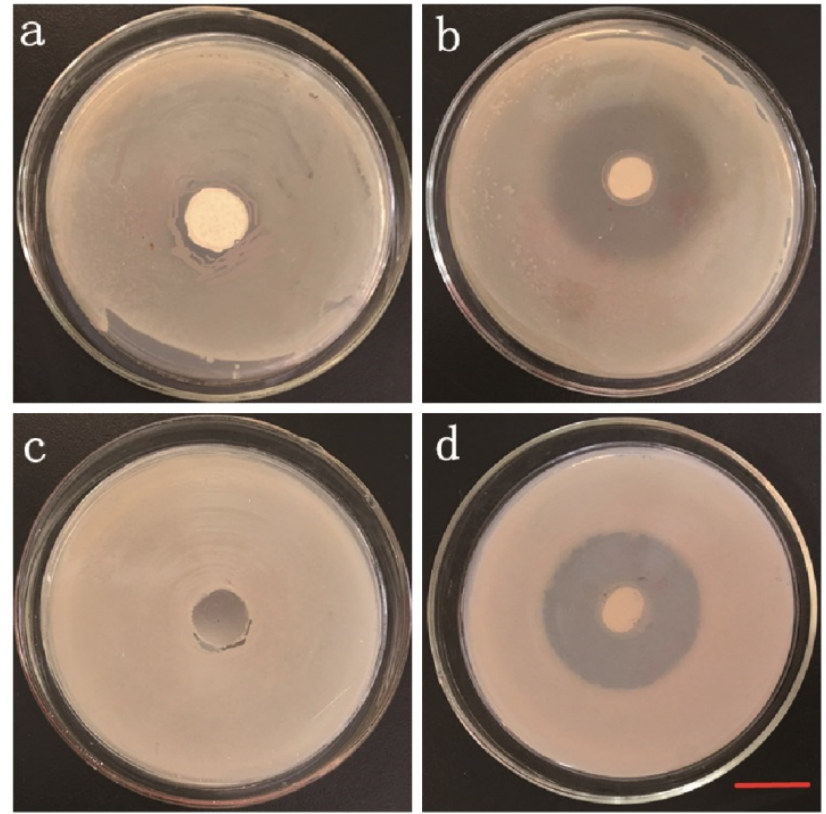

Figure 8. Antibacterial activities of selected fiber samples: (a) $\mathrm{GS}_{3}{ }^{-} / \mathrm{P}^{-}$against E.coli; (b) $\mathrm{GS}_{3}{ }^{+} / \mathrm{P}^{+}$against E.coli; (c) $\mathrm{GS}_{3}{ }^{-} / \mathrm{P}^{-}$against $S$. aureus; and, (d) $\mathrm{GS}_{3}{ }^{+} / \mathrm{P}^{+}$against $S$. aureus solid medium. Scale bar: $2 \mathrm{~cm}$. 

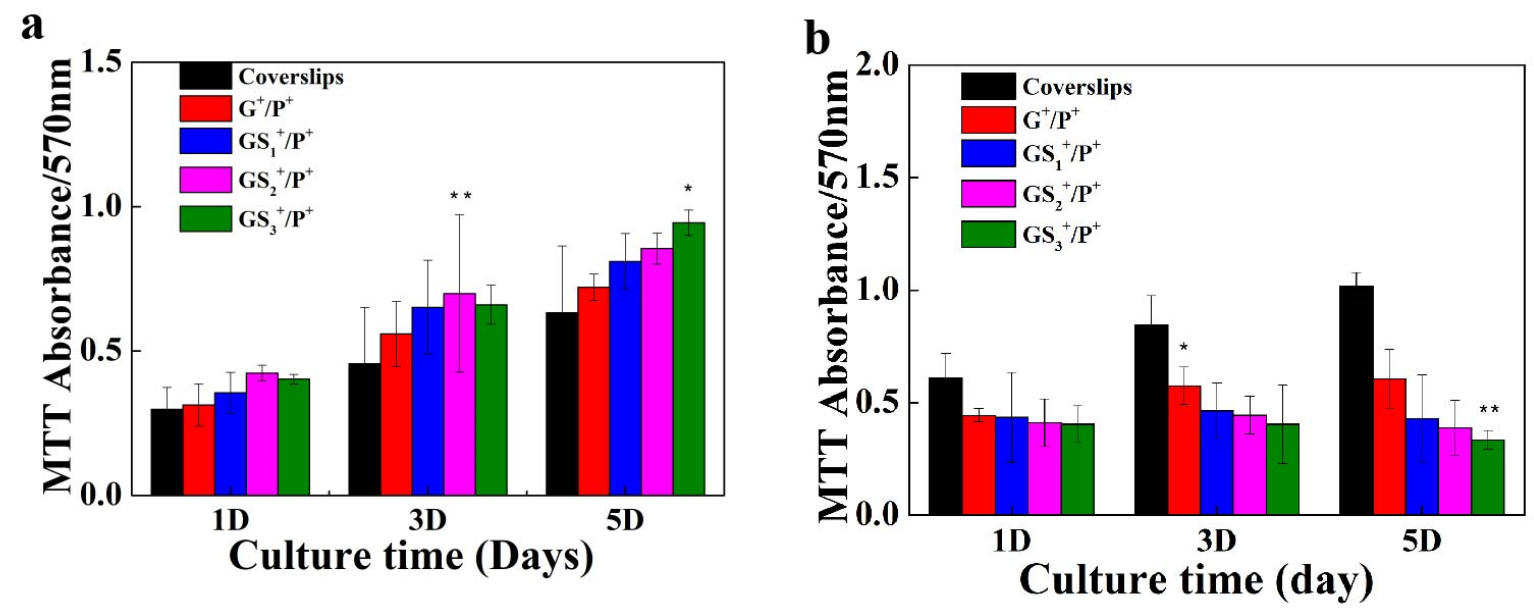

Figure 9. (a) L929 and (b) SMMC-7721 cell proliferation on the drug-loaded fibers. * denotes $\mathrm{p}<0.05$ and $* * \mathrm{p}<$ 0.01 when compared with the blank coverslips. 

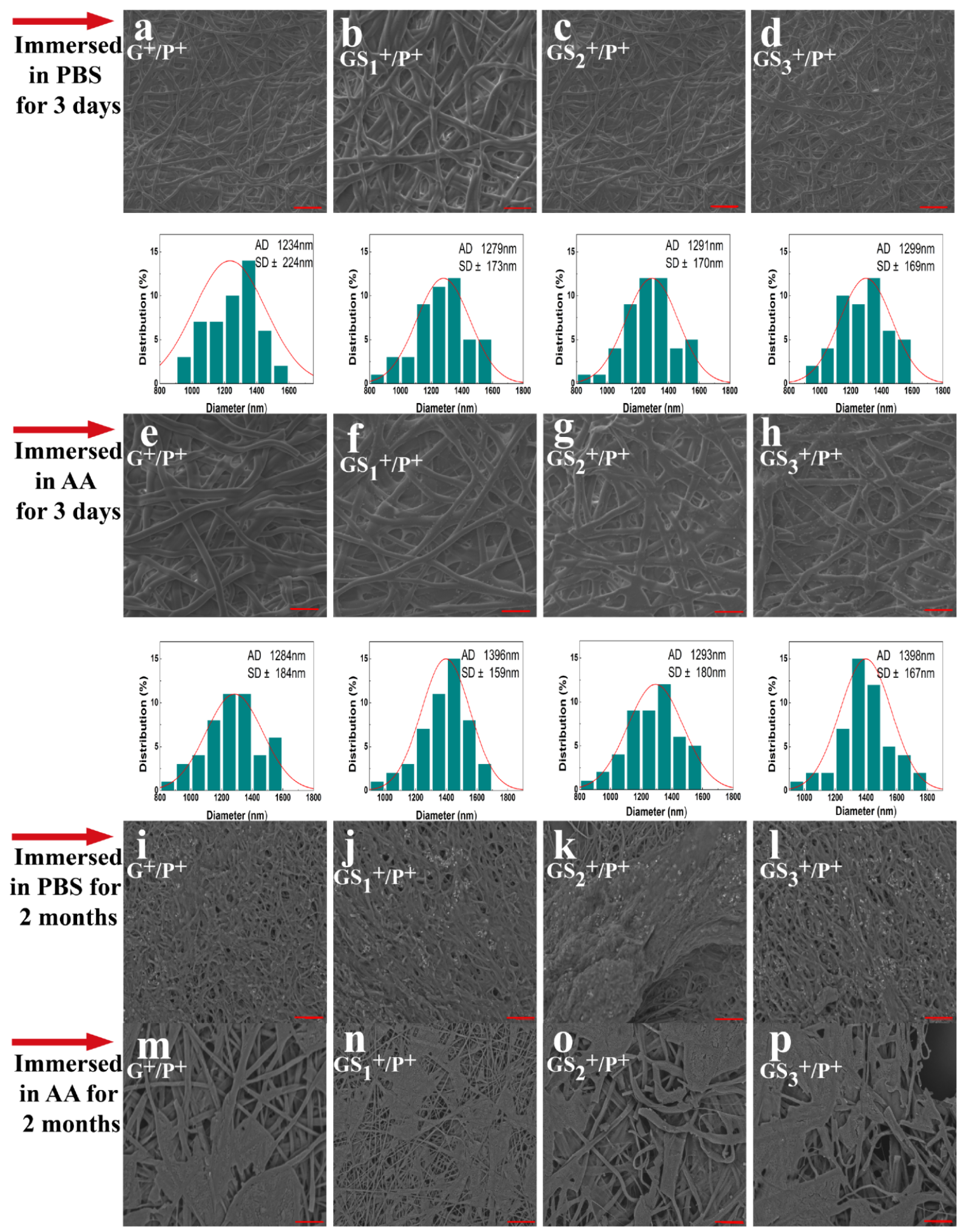

Figure 10. SEM images of fiber scaffolds after degradation studies. Images and fiber diameter distributions (AD:

mean diameter; SD standard deviation) are shown for (a) $\mathrm{G}^{+} / \mathrm{P}^{+}$; (b) $\mathrm{GS}_{1}{ }^{+} / \mathrm{P}^{+}$; (c) $\mathrm{GS}_{2}{ }^{+} / \mathrm{P}^{+}$; and (d) $\mathrm{GS}_{3}{ }^{+} / \mathrm{P}^{+}$

after 3 days immersion in PBS, and (e-h) for the same fibers after 3 days in AA. Results obtained after two months' immersion are given in (i-l) for PBS and (m-p) for AA (pH 5.0). Scale bar: $5 \mu \mathrm{m}$. 


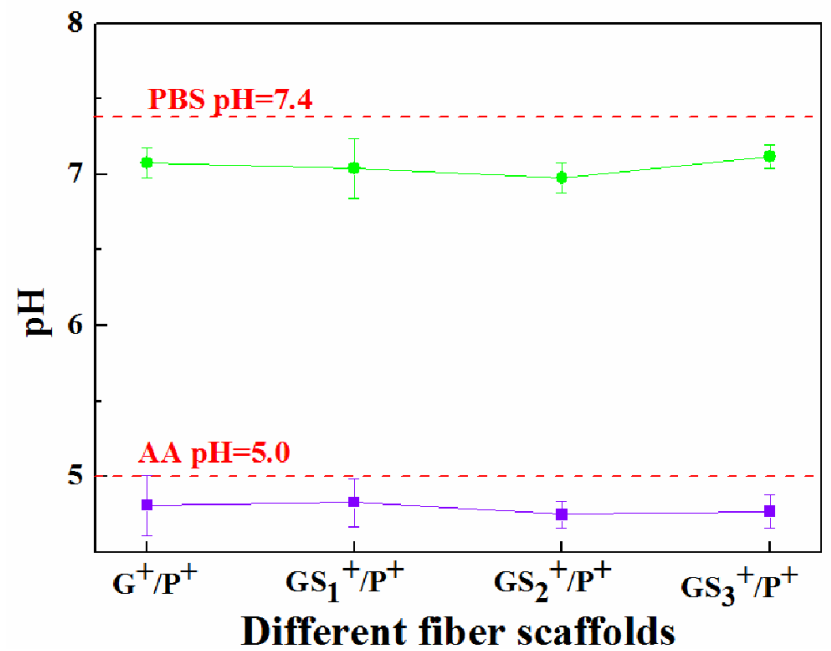

Figure 11. The $\mathrm{pH}$ values of buffer solutions after two months in contact with the fiber scaffolds. 


\section{Tables}

Table 1. Details of the electrospinning solutions used in this study. "G" denotes gelatin, "P" PLCL, and "S" sodium bicarbonate; "+" indicates systems with a drug loading, and "-" those without drug.

\begin{tabular}{cccccc}
\hline & \multicolumn{3}{c}{ Shell solution } & \multicolumn{2}{c}{ Core solution } \\
\cline { 2 - 6 } Sample & $\begin{array}{c}\text { Gelatin } \\
\text { conc } \\
\end{array}$ & $\begin{array}{c}\text { SB conc } \\
(\mathbf{w} / \mathbf{v})\end{array}$ & $\begin{array}{c}\text { Ciprofloxacin } \\
\mathbf{c o n c} \\
(\mathbf{w} / \mathbf{v})\end{array}$ & $\begin{array}{c}\text { PLCL } \\
\mathbf{c o n c} \\
(\mathbf{w} / \mathbf{v})\end{array}$ & $\begin{array}{c}\text { DOX conc } \\
(\mathbf{w} / \mathbf{v})\end{array}$ \\
\hline Gelatin & & & $10 \%$ & - & - \\
$\mathrm{PLCL}^{+}$ & $15 \%$ & $5 \%$ & - & $5 \%$ & $1 \%$ \\
$\mathrm{G}^{+} / \mathrm{P}^{+}$ & - & - & $10 \%$ & $5 \%$ & $1 \%$ \\
$\mathrm{GS}_{1}{ }^{+} / \mathrm{P}^{+}$ & $15 \%$ & - & $10 \%$ & $5 \%$ & $1 \%$ \\
$\mathrm{GS}_{2}{ }^{+} / \mathrm{P}^{+}$ & $15 \%$ & $1 \%$ & $10 \%$ & $5 \%$ & $1 \%$ \\
$\mathrm{GS}_{3}{ }^{+} / \mathrm{P}^{+}$ & $15 \%$ & $5 \%$ & $10 \%$ & $5 \%$ & $1 \%$ \\
$\mathrm{GS}_{4}{ }^{+} / \mathrm{P}^{+}$ & $15 \%$ & $7 \%$ & $10 \%$ & $5 \%$ & $1 \%$ \\
$\mathrm{Gelatin}^{-}$ & $15 \%$ & $5 \%$ & - & - & - \\
$\mathrm{PLCL}^{-}$ & - & - & - & $5 \%$ & - \\
$\mathrm{GS}_{1}-/ \mathrm{P}^{-}$ & $15 \%$ & $1 \%$ & - & $5 \%$ & - \\
$\mathrm{GS}_{2}{ }^{-} / \mathrm{P}^{-}$ & $15 \%$ & $3 \%$ & - & $5 \%$ & - \\
$\mathrm{GS}_{3}{ }^{-} / \mathrm{P}^{-}$ & $15 \%$ & $5 \%$ & - & $5 \%$ & - \\
\hline
\end{tabular}

Table 2. The contact-angles of the cross-linked fiber scaffolds.

\begin{tabular}{cccc}
\hline Sample & Contact-angle & Sample & Contact-angle \\
\hline Gelatin $^{+}$ & $28 \pm 4.3^{\circ}$ & Gelatin & $32 \pm 3.6^{\circ}$ \\
$\mathrm{PLCL}^{+}$ & $121 \pm 3.5^{\circ}$ & $\mathrm{PLCL}^{-}$ & $124 \pm 2.7^{\circ}$ \\
$\mathrm{G}^{+} / \mathrm{P}^{+}$ & $33 \pm 4.1^{* *}$ & $\mathrm{G}^{-} / \mathrm{P}^{-}$ & $35 \pm 2.8^{\circ *}$ \\
$\mathrm{GS}_{1}{ }^{+} / \mathrm{P}^{+}$ & $21 \pm 2.7^{* *}$ & $\mathrm{GS}_{1}-/ \mathrm{P}^{-}$ & $23 \pm 4.2^{\circ *}$ \\
$\mathrm{GS}_{2}{ }^{+} / \mathrm{P}^{+}$ & $11 \pm 2.3^{\circ *}$ & $\mathrm{GS}_{2}-/ \mathrm{P}^{-}$ & $12 \pm 0.2^{\circ *}$ \\
$\mathrm{GS}_{3}{ }^{+} / \mathrm{P}^{+}$ & $10 \pm 1.2^{0^{* *}}$ & $\mathrm{GS}_{3}-/ \mathrm{P}^{-}$ & $12 \pm 1.1^{\circ *}$ \\
\hline
\end{tabular}

* denotes $\mathrm{p}<0.05$ when compared with the monolithic PLCL fibers.

Table 3. Tensile strength data.

\begin{tabular}{cccccc}
\hline Sample & $\begin{array}{c}\text { Break } \\
\text { stress } \\
(\mathbf{M P a})\end{array}$ & $\begin{array}{c}\text { Break } \\
\text { elongation } \\
(\%)\end{array}$ & Sample & $\begin{array}{c}\text { Break } \\
\text { stress } \\
(\mathbf{M P a})\end{array}$ & $\begin{array}{c}\text { Break } \\
\text { elongation } \\
(\%)\end{array}$ \\
\hline Gelatin $^{+}$ & $1.48 \pm 0.2$ & $22.5 \pm 1.1$ & Gelatin & $1.49 \pm 0.1$ & $21.5 \pm 1.2$ \\
$\mathrm{PLCL}^{+}$ & $3.13 \pm 0.3$ & $5.09 \pm 1.1$ & $\mathrm{PLCL}^{-}$ & $3.03 \pm 0.3$ & $6.09 \pm 1.3$ \\
$\mathrm{G}^{+} / \mathrm{P}^{+}$ & $2.00 \pm 0.3$ & $25.8 \pm 1.7^{*}$ & $\mathrm{G}^{-} / \mathrm{P}^{-}$ & $2.30 \pm 0.7$ & $27.1 \pm 1.9^{*}$ \\
$\mathrm{GS}_{1}{ }^{+} / \mathrm{P}^{+}$ & $2.09 \pm 0.4$ & $24.7 \pm 0.6$ & $\mathrm{GS}_{1}{ }^{-} / \mathrm{P}^{-}$ & $2.20 \pm 0.5$ & $25.8 \pm 0.9$
\end{tabular}




$\begin{array}{llllll}\mathrm{GS}_{2}{ }^{+} / \mathrm{P}^{+} & 2.21 \pm 0.7 & 22.2 \pm 1.1 & \mathrm{GS}_{2}^{-} / \mathrm{P}^{-} & 2.03 \pm 0.4 & 25.3 \pm 1.3 \\ \mathrm{GS}_{3}{ }^{+} / \mathrm{P}^{+} & 2.57 \pm 0.2^{\#} & 24.3 \pm 0.8 & \mathrm{GS}_{3}{ }^{-} / \mathrm{P}^{-} & 2.10 \pm 0.3 & 25.9 \pm 1.4\end{array}$

* denotes $\mathrm{p}<0.05$ when compared with the monolithic PLCL fibers, \# denotes $\mathrm{p}<0.05$ when compared with the monolithic gelatin fibers.

Table 4. The maximum extent of release reached by the various fibers under different $\mathrm{pH}$ conditions.

\begin{tabular}{ccccccc}
\hline \multirow{2}{*}{ Drug } & Buffer & $\begin{array}{c}\text { Max } \\
\text { release } \\
\text { reached } \\
\text { after }\end{array}$ & $\mathrm{G}^{+} / \mathrm{P}^{+}$ & $\mathrm{GS}_{1}+/ \mathrm{P}^{+}$ & $\mathrm{GS}_{2}{ }^{+} / \mathrm{P}^{+}$ & $\mathrm{GS}_{3}{ }^{+} / \mathrm{P}^{+}$ \\
\hline \multirow{2}{*}{ Ciprofloxacin } & PBS & $32 \mathrm{~h}$ & $41 \pm 1$ & $43 \pm 1$ & $50 \pm 0.5$ & $52 \pm 0.8$ \\
\cline { 2 - 7 } & $\mathrm{AA}$ & $31 \mathrm{~h}$ & $41 \pm 1$ & $71 \pm 2$ & $75 \pm 1$ & $80 \pm 0.4$ \\
\hline \multirow{2}{*}{ DOX } & PBS & 26 days & $30 \pm 2$ & $38 \pm 2$ & $41 \pm 0.8$ & $45 \pm 0.7$ \\
\cline { 2 - 7 } & AA & 32 days & $30 \pm 1$ & $52 \pm 0.9$ & $61 \pm 1$ & $67 \pm 1$ \\
\hline
\end{tabular}

Table 5. Inhibition zone diameters for the coaxial fiber scaffolds.

\begin{tabular}{ccc}
\hline Sample & $\begin{array}{c}\text { Inhibition zone with } \\
\text { E. coli }(\mathbf{m m})\end{array}$ & $\begin{array}{c}\text { Inhibition zone with } \\
\text { S. aureus }(\mathbf{m m})\end{array}$ \\
\hline Gelatin $^{+}$ & $30 \pm 2.7$ & $31 \pm 4.4$ \\
$\mathrm{PLCL}^{+}$ & $28 \pm 1.5$ & $29 \pm 1.9$ \\
$\mathrm{GS}_{1}^{+} / \mathrm{P}^{+}$ & $33 \pm 3.8$ & $34 \pm 3.0$ \\
$\mathrm{GS}_{2}^{+} / \mathrm{P}^{+}$ & $35 \pm 3.9$ & $36 \pm 2.4^{\#}$ \\
$\mathrm{GS}_{3}{ }^{+} / \mathrm{P}^{+}$ & $37 \pm 2.2^{*}$ & $38 \pm 4.1$ \\
$\mathrm{Gelatin}^{-}$ & - & - \\
$\mathrm{PLCL}^{-}$ & - & - \\
$\mathrm{GS}_{1}^{-} / \mathrm{P}^{-}$ & - & - \\
$\mathrm{GS}_{2}^{-} / \mathrm{P}^{-}$ & - & - \\
$\mathrm{GS}_{3}{ }^{-} / \mathrm{P}^{-}$ & - & - \\
\hline
\end{tabular}

* denotes $\mathrm{p}<0.05$ when compared with the monolithic PLCL fibers, \# denotes $\mathrm{p}<0.05$ when compared with the monolithic gelatin fibers. 